\title{
Uma proposta em ensino de física e a democratizaçao do debate nuclear
}

\section{A Proposal in Physics Teaching and the Democratization of the Nuclear Debate}

\author{
Paulo Sérgio Gai Montedo ${ }^{1}$, José Ricardo Marinelli ${ }^{2}$ \\ ${ }^{1}$ Departamento de Química, Instituto Federal de Santa Catarina, Campus Criciúma/SC, \\ CEP 88813-600 \\ ${ }^{2}$ Departamento de Física, Universidade Federal de Santa Catarina, Florianópolis/SC, CEP \\ $88040-900$
}

\section{Resumo}

De acordo com dados do Plano Nacional de Energia, até o ano de 2030 o Brasil tem a intenção de construir quatro usinas nucleares e até o ano 2050 serão outras oito, totalizando quinze usinas termonucleares em funcionamento no país. Compreendendo a falta de informações ao público em geral e a inexistência de discussões conjuntas aos diversos setores que compõem a sociedade brasileira, o trabalho presente, realizado em uma escola pública estadual em Florianópolis/SC, teve como objetivo encorajar nossos estudantes a reivindicarem-se enquanto parte das discussões e debates no que concerne à temática da nucleoeletricidade. Neste sentido, assumindo a dialeticidade entre o técnico e político nestas discussões, partilhamos, no contexto da sala de aula, da experiência que tivemos na produção e aplicação de um material instrucional relacionado à radioatividade e aos princípios de funcionamento das usinas nucleares de Angra dos Reis. Buscamos, desta maneira, no campo da Física, desconstruir algumas concepções comuns equivocadas, difundidas inclusive pelos meios de comunicação e reproduzidas pelo público em geral, sobre algumas especificidades da radiação e o processo de produção de eletricidade via energia nuclear. Por conseguinte, nos foi possível problematizar alguns mitos relacionados a uma suposta neutralidade no processo de produção do conhecimento científico e tecnológico, o qual, sob uma perspectiva de supremacia tecnocrática, alija a sociedade do seu direito à participação nos debates e decisões da área, assim como, sob o pilar salvacionista, aponta a energia nuclear como a solução de todos os nossos problemas frente à crise energética e ambiental que se acentuará nas próximas décadas. Enfim, amparado na necessidade de qualificação dos nossos jovens às discussões e democratização do debate aos diversos setores da sociedade, segue aqui uma proposta exequível de ensino $e$ aprendizagem sobre a temática, na rede de ensino médio.

Palavras-chave: Radioatividade. Usinas Nucleares. Ciência, Tecnologia e Sociedade. 


\begin{abstract}
According to the National Energy Plan, by the year 2030, Brazil intends to build four nuclear plants and by the year 2050, there will be another eight, in a total of fifteen thermonuclear plants in operation in the country. Understanding the lack of information to the general public and the lack of joint discussions with the various sectors that compose Brazilian society, the present work, carried out in a state public school in Florianópolis / SC, aimed to encourage our students to claim themselves as part of the discussions and debates on nuclear power issues. In this sense, assuming the dialectic between technician and politician in these discussions, we share, in the context of the classroom, the experience we had in the production and application of an instructional material related to the radioactivity and the operating principles of the Angra dos Reis nuclear power plants. In this way, we have sought to deconstruct some common misconceptions, which are even disseminated by the media and reproduced by the public in general, on some specificities of radiation and the process of producing electricity through nuclear energy. Therefore, it was possible to problematize some myths related to a supposed neutrality in the process of production of scientific and technological knowledge, which, from a perspective of technocratic supremacy, deprives society of its right to participate in the debates and decisions of the area. Under the pillar of salvation, it points to nuclear energy as the solution to all our problems in the face of the energy and environmental crisis that will be intensify in the coming decades. Finally, based on the need to qualify our youth to the discussions and democratization of the debate to the various sectors of society, here follows a feasible proposal of teaching and learning on the subject at the high school level.
\end{abstract}

Keywords: Radioactivity. Nuclear power plants. Science, Technology and Society.

\title{
I. INTRODUÇÃOO
}

Educar é também compreender e fazer-se compreender sobre a relação entre o progresso e os sucessos tecnológicos alcançados pela humanidade e a construção social de uma situação de risco e vulnerabilidade nunca antes vista na história do nosso processo civilizatório. É assim, perceber a ciência enquanto elemento catalizador das mudanças de um mundo em constante transformação e a necessidade de nos repensarmos enquanto sujeitos desta mudança.

Tais mudanças, aceleradas e universais, são características permanentes dos tempos modernos, implicando novos desafios nas dimensões da formação dos nossos jovens que integram as diversas etapas do ensino nas escolas brasileiras. Postman e Weingartner (1971, p.13), há quase cinco décadas, já alertavam que de um modo geral, a sobrevivência da nossa sociedade está ameaçada por um número crescente de problemas inéditos e, até a data, insolúveis, tornando-se necessária uma educação que vise na juventude a construção de competências e a aplicação de estratégias na luta pela sobrevivência em um mundo repleto de conflitos, incertezas e oportunidades sem precedentes. As ideias de Casti (2012) parecem apontar para um cenário em que os níveis exponencialmente crescentes de complexidade das infraestruturas básicas à manutenção da sociedade moderna tornam a máxima de Postman 
e Weingartner ainda mais atual. De acordo com o autor, existe uma indiscutível fragilidade e consequente armadilha no entrelaçamento dos sistemas que sustentam o nosso estilo de vida, no qual a energia, a água, a comida, a comunicação, o transporte, a saúde, a segurança, as finanças, são tão interligadas que se assemelham metaforicamente a um castelo de cartas, um apoiado sobre o outro, e se um sistema espirrar, os demais correm o risco de contrair uma pneumonia na mesma hora. Consequentemente, nos perguntamos: que tipo de valores, atitudes, aptidões e saberes estamos propiciando à nossa juventude ${ }^{1}$, que os auxiliem à sobrevivência neste mundo em rápida transformação?

Compreendendo a ciência enquanto um constructo histórico, social, cultural e humano, torna-se pertinente afirmar a abordagem temática, no contexto do ensino de ciências, enquanto importante ferramenta na construção de caminhos possíveis para uma educação como prática libertadora ${ }^{2}$. Autores como Auler e Delizoicov (2001), Auler (2002), defendem em seu trabalho um programa de ensino realizado por meio da utilização de temáticas inerentes à sociedade contemporânea e que problematizem questões controversas relacionadas à Ciência e Tecnologia $(C \& T)$. Salientam que, quando seguidos determinados critérios, podem vir a desvelar alguns mitos relacionados a uma visão de neutralidade da $C$ \& $T$ na sociedade. Ainda de acordo com os autores, estes mitos se manifestam por discursos de fundo calcados sob uma superteoria do progresso; uma perspectiva salvacionista da C \& T; assim como uma apropriação positivista do ideário tecnocrático, onde há incutido uma suposta supremacia aos detentores do saber científico no processo de decisões de temas envolvendo $\mathrm{C} \& \mathrm{~T}$.

De acordo com documentos oficiais da Empresa de Pesquisas Energéticas (EPE, 2007), consta no Plano Nacional de Energia - PNE 2030 - que o Brasil, até o ano de 2030, além de Angra 1 e 2 já em funcionamento e Angra 3 em fase final de construção, pretende construir quatro usinas nucleares, sendo duas no sudeste e duas no nordeste. Somando-se a isso, conforme o PNE 2050 (EPE, 2015), estão planejadas outras oito termonucleares nos 20 anos seguintes, totalizando um conjunto de quinze usinas nucleoelétricas em funcionamento no país, ou seja, um aumento significativo da oferta. Embora a conjuntura de crise econômica e os deflagrados casos de corrupção imputados à Eletronuclear e Petrobrás sejam elementos retardadores na expansão do setor, acreditamos que o governo brasileiro não pretenda incorrer em erros semelhantes aos que levaram à grande crise no sistema elétrico do país em $2001^{3}$,tornando o debate inevitável. Sob a óptica do modo de produção vigente, atrelada a um crescimento demográfico acelerado, a retomada do crescimento na economia

\footnotetext{
${ }^{1}$ De acordo com o documento disponibilizado pelo Ministério da Educação (MEC), em abril de 2016, enquanto proposta preliminar para a Base Nacional Comum Curricular (BNCC), entende-se juventude como uma condição sócio-histórico-cultural, plural e em constante transformação, imersa em questões do seu tempo, participante ativa do processo de formação que deve levar a sua autônoma e critica inserção no mundo, logo, com importante função na definição dos rumos que a sociedade irá seguir (BNCC, 2016, p.488).

${ }^{2}$ A educação como prática da liberdade, ao contrário daquela que é a prática da dominação, implica a negação do homem abstrato, isolado, solto, desligado do mundo, assim também a negação do mundo como uma realidade ausente dos homens. (FREIRE, 1987, p.81)

${ }^{3} \mathrm{O}$ fenômeno ficou conhecido como apagão e surge em um contexto de crise econômica e necessidade do governo em reduzir o déficit das contas públicas. Para TOLMASQUIM (2000), naquele período, havia um descompasso entre o crescimento da demanda e o crescimento da oferta elétrica, o que resultou no corte de investimentos no setor e uma insignificante expansão do sistema elétrico em sua capacidade de geração e transmissão de energia.
} 
brasileira, conforme os PNEs, conjuntamente ao aumento da demanda de energia para o setor produtivo, implicam no agravamento de uma crise energética sem precedentes para as próximas décadas. Guimarães e Mattos (2011), autoridades na área, apontam a manutenção do percentual de oferta nuclear na matriz energética brasileira enquanto uma política necessária e estratégica para o setor. Segundo os autores, as grandes reservas de urânio contidas em território nacional; o domínio tecnológico do Brasil sobre o ciclo do combustível nuclear; a alta capacidade de geração ininterrupta de energia; as mudanças climáticas no que concerne ao Aquecimento Global e a emissão de CO2; assim como a economia e o diferencial competitivo do país na produção de energia; são fatores que contribuem a esta visão.

Quando falamos de uma expansão significativa na produção de eletricidade do país nos moldes das usinas nucleares, ponto que carrega consigo uma grande carga de afetividade e resistência da população em geral, cristaliza-se a importância de nós, educadores, compreendermos a indispensabilidade da realização de amplos debates sobre o tema, em especial junto à nossa juventude. De forma serena, é preciso dialogarmos sobre os desafios que implicam tais escolhas. Ao nosso ver, este debate demanda uma decisão com aspectos técnicos sim, mas, indubitavelmente, é um debate que admite diversos pontos de vista, amplo e com escolhas que irão determinar uma extensa janela de tempo para as futuras gerações, ou seja, trata-se de um debate com origem política, demandando, portanto, de uma decisão coletiva envolvendo todos os cidadãos deste país.

Como quase via de regra, a população tem sido colocada à parte destas discussões e o discurso tem prevalecido sob o argumento de que o povo é ignorante em matéria de conhecimento sobre o assunto, sendo esta uma discussão muito complexa e, portanto, pertencendo estas decisões aos especialistas da área. A eles, seria possível uma suposta neutralidade, tornando-os os únicos aptos a se posicionarem quando as discussões permeiam temas de ordem científica e tecnológica. Discordamos de maneira veemente desta afirmação, e mais, alertamos que esta visão esconde, nas suas entrelinhas, uma forma de ver o mundo onde a população é alijada do seu direito de escolha, do processo democrático, e abduzida de um furacão de discussões que, uma hora ou outra, trilha um caminho comum às linhas gerais sobre o modelo de sociedade em que vivemos, mas principalmente, o modelo de sociedade que queremos.

Desta forma, questões cada vez mais interligadas no seu horizonte político e técnico se entrelaçam diante da necessidade de ampliarmos significativamente a participação da população nos debates e escolhas que determinarão os rumos da nossa sociedade. Uma educação com viés crítico e emancipador das mulheres e homens que compõe o nosso corpo social, deve compreender, também no âmbito científico e tecnológico, a construção dos saberes enquanto pilares de sustentação teórica, e porque não, prática, da práxis política de uma juventude em busca da sua cidadania. Tendo em vista tais informações, buscamos no desenvolver deste trabalho, evidenciar a urgência e inevitabilidade de nos apropriarmos deste debate, enquanto sujeitos da nossa própria história, em seus aspectos tecnopolíticos. Admitir a reciprocidade entre o caráter técnico e político na discussão que envolve a produção nucleoelétrica, significa reconhecer não só a participação da população como elemento fundamental à manutenção do exercício democrático, mas também, que alguns aspectos técnicos da área são imprescindíveis para um debate com qualidade e 
serenidade na análise dos fatos. Veiga (2011), no seu livro Energia Nuclear, do Anátema ao Diálogo alerta que em sua vida acadêmica, durante palestras e seminários, mesmo quando em ambiente universitário e de pós-graduação, não é raro notar que alguns participantes chegam a ignorar até mesmo a diferença entre fissão e fusão nuclear e salienta que um debate com tais dimensões exige daqueles que o fazem o compromisso ético de lutar para que a retórica afetiva não sufoque a fria análise dos fatos (VEIGA, 2011, p.7). Desta forma, nos propusemos a iniciar um movimento contínuo na compreensão dos conhecimentos comuns à radioatividade e aos princípios de funcionamento das usinas nucleares brasileiras, na área da Física, que viriam a qualificar nossos jovens, discentes do ensino médio, nos debates e tomadas de decisões referentes à produção de energia nucleoelétrica no Brasil.

O presente trabalho, carrega entre os seus objetivos um esforço partilhado pela comunidade de físicos na incorporação de temas relacionados à Física Contemporânea no cotidiano de sala de aula do ensino médio. Para isso, por meio de uma temática traçada mediante a compreensão de conhecimentos sobre a Radioatividade e as Usinas Nucleares Brasileiras, dando ênfase à proposta do Mestrado Profissional em Ensino de Física, nos propusemos no decorrer do projeto a realizar uma discussão aberta sobre o tema, aliando uma determinada rigorosidade dos saberes científicos necessários à sua compreensão, a necessidade de democratização do debate nuclear na sociedade.

\section{Metodologia}

Como ponto de partida, nos dedicamos a tentar compreender, a partir do campo de saberes dos estudantes com quem iríamos trabalhar nos meses seguintes, quais os conhecimentos e mecanismos pedagógicos poderiam vir a serem relevantes para a construção de um plano de ensino, a ser implementado posteriormente, que evidenciasse esta relação dialética entre o caráter tecnicista, incutido na forma à qual a sociedade reproduz a questão nuclear, e os aspectos sociais e coletivos que abarcam as discussões sobre o tema em suas diferentes dimensões. Para isso, por meio de um estudo dos trabalhos de Cunha \& Silva (2009); Rzyski \& Sartori (1997); Tanimoto (2014); Barragam, Mortimer e Leal (2009); construímos e aplicamos um questionário junto a duas turmas do segundo ano do ensino médio. Tal questionário contou com trinta questões divididas em quatro eixos: (1) Compreensões sobre radiação e radioatividade; (2) Energia nuclear e os rejeitos radioativos; (3) A produção de energia elétrica no Brasil; (4) Mitos da neutralidade científica. A cada um destes eixos tivemos um misto de questões do tipo diretas, com objetivo meramente exploratório, assim como afirmações propostas por meio de uma escala de opiniões do tipo Likert, a qual mediante um conjunto de assertivas, buscou-se fazer com que os estudantes assumissem posturas e atitudes diante de pontos polêmicos e controversos neste debate. Detalhes deste questionário, assim como uma análise de seu resultado e discussões, estão disponíveis no trabalho de mestrado de Montedo, P.S.G (2017).

Em um segundo momento, a partir do levantamento e análise dos dados do questionário, além de uma ampla pesquisa nos materiais instrucionais e literaturas sobre o assunto, em especial as apostilas disponibilizadas pelo Comissão Nacional de Energia Nuclear (CNEM), nos propusemos a traçar as linhas gerais que nortearam a construção do material instrucional utilizado no projeto. Neste material desenvolvemos didaticamente alguns conhecimentos 
entrelaçados entre as disciplinas de Física e Química; apresentamos curiosidades sobre o assunto; desconstruímos concepções equivocadas sobre a radioatividade e a energia nuclear; disponibilizamos informações com o objetivo de fomentar um debate sobre ciência, tecnologia e sociedade, suas prioridades e mecanismos de reprodução de acordo com as necessidades do mercado; enfatizamos a participação popular em suas discussões enquanto elemento fundamental à manutenção democrática dos seus direitos enquanto indivíduos e coletivo; apresentamos os princípios tecnológicos de funcionamento dos reatores nucleares em Angra dos Reis, além de compararmos os erros de projeto que levaram aos acidentes nucleares de Fukushima e Chernobyl à realidade brasileira. É preciso salientarmos as nossas limitações diante do alto nível interdisciplinar da questão. Um trabalho conjunto, envolvendo profissionais de outras áreas do conhecimento, certamente pode gerar produtos didáticos fascinantes.

Dando seguimento, durante um período de aproximadamente 2 meses, ao longo de 28 horas-aulas ${ }^{4}$, foi desenvolvida esta temática junto a uma turma do terceiro ano do ensino médio na Escola de Educação Básica Simão José Hess, em Florianópolis/SC. Este grupo de alunos participou da pesquisa de campo (questionário) que deu corpo, objetivo e subjetivo, à construção do material didático, produto deste trabalho.

Para isto, durante o projeto, o espaço de ensino e aprendizagem foi ampliado, isto é, no período normal de aula, matutino, ao longo de 20 horas-aulas, tivemos como base um plano de estudos conjunto ao material instrucional, o qual foi impresso e disponibilizado a cada estudante. Já no período da tarde, como atividade paralela ao horário de aula habitual, isto é, extraclasse, construímos quatro momentos destinados à exibição e debate de documentários envolvendo a temática nuclear ${ }^{5}$. Estes círculos de discussões ocorreram a cada quinze dias e foram batizados pela turma como Cine Nuclear.

\section{Desenvolvendo A TEMÁticA}

O desenvolvimento da temática assume alguns momentos fundamentais à sua execução. Como etapa inicial, temos a problematização e justificação junto à turma da necessidade de ampliarmos nossos conhecimentos sobre Energia Nuclear. Em seguida, passamos à fase de apropriação de alguns conhecimentos físicos e técnicos relacionados ao tema e qualificação dos debates que ocorriam de maneira concomitante às aulas no espaço do Cine Nuclear. Por fim, a turma produziu vídeos e organizou uma tenda para debater a energia nuclear no Brasil durante a mostra cultural realizada na escola.

\section{Aspectos Gerais}

Não é raro presenciarmos discussões ou mesmo informações, nos diversos meios de comunicações, que ignoram conhecimentos básicos, fundamentais à argumentação, propalando medo, preconceito e construindo mistificações comuns e errôneas à forma como nos relacionamos com os temas da radiação e energia nuclear. Desta forma, no contexto

\footnotetext{
${ }^{4}$ Uma hora-aula, no contexto de ensino deste projeto, equivale a um tempo de 45 minutos.

${ }^{5}$ Vídeos exibidos e discutidos: Hiroshima, o dia seguinte; O Desastre de Chernobyl; Segundos Fatais - A Usina Nuclear de Fukushima; Linha Direta Justiça - O Acidente Radiológico com Césio 137 em Goiânia.
} 
da sala de aula, reconstruir alguns destes conhecimentos foi uma das tarefas deste trabalho, por exemplo: As explosões no interior dos reatores de Fukushima e Chernobyl não foram explosões nucleares, dado que, mesmo fora de controle, uma usina nuclear não pode tornar-se uma bomba atômica; A radiação não é necessariamente nociva ao ser humano, pelo contrário, sem ela provavelmente não haveria vida humana na Terra. Ademais, todo corpo emite radiação; $\mathrm{O}$ conhecimento em energia nuclear de forma alguma é dispensável à humanidade. Como exemplo disto temos a Medicina Nuclear que salva a vida de milhares de pessoas todos os anos; Nenhum projeto de Usina Nuclear é à prova de erros. A energia elétrica obtida por termonucleares não se sustenta, em um sentido amplo, como um processo de produção de energia limpa ${ }^{6}$. Para desconstruir isto, basta lembrar que parte dos seus rejeitos permanecerão em atividade por milhões de anos e que até o momento não existe em local algum do planeta um depositório definitivo para estes. Além do que, os impactos ambientais de acidentes envolvendo esta tecnologia podem perdurar por décadas, séculos, ou até mesmo, milênios.

Por conseguinte, ousamos desenvolver uma proposta pedagógica que buscasse oportunizar situações de ensino e aprendizagem à juventude, que viessem a: (i) despertar a curiosidade sobre o assunto; (ii) capacitá-los ao exercício do diálogo e análise de posições divergentes; (iii) fazerem valer suas reivindicações afim de se inserirem nos debates e decisões sobre o tema; (iv) desenvolver valores e atitudes de modo a contribuírem nesta e em outras discussões e decisões sobre temas controversos, inerentes à sociedade contemporânea. Apresentamos a seguir, alguns elementos do passo a passo à aplicação da sequência didática e demais atividades realizadas junto ao grupo de alunos escolhido.

\section{Motivação sobre o tema}

As quatro primeiras aulas tiveram papel fundamental na motivação da turma. Durante a primeira e segunda semana, ambas com duas aulas simultâneas, utilizamos como pontapé inicial o texto de abertura do material didático, construído por nós, com título Carta ao Estudante: Precisamos debater nossa opção nuclear (MONTEDO; 2017). No corpo deste texto, procuramos introduzir discussões envolvendo alguns mitos sobre a radioatividade; a intenção de construção de 12 usinas nucleares no país até 2050; o problema relacionado aos rejeitos radioativos como subproduto da utilização da energia nuclear; e acidentes conhecidos na área. Para esta tarefa, a turma foi dividida em grupos, onde lhes foi dada a responsabilidade de leitura, discussão e posterior socialização dos debates com o restante da sala.

Durante a exposição dos pontos de vista e questionamentos sobre o texto, observamos que o tema radioatividade, para a maioria dos grupos, manifestava-se mediante um discurso de medo. Além disso, houve uma aversão, quase que generalizada, a construção de novas usinas nucleares no país. Entretanto, teve também quem defendesse a construção das usinas, argumentando, em linhas gerais, sob um discurso de menor dano, de um caminho

\footnotetext{
${ }^{6}$ A concepção do termo Energia Limpa, para parte da comunidade científica, implica naquela em que no seu processo de produção a emissão de CO2 e outros gases responsáveis pelo agravamento do efeito estufa são insignificantes. No entanto, ao nosso ver, o termo carrega consigo uma carga subjetiva atrelada à ideia de confiabilidade, ausência de perigo e sem impacto relevante sobre o meio ambiente
} 


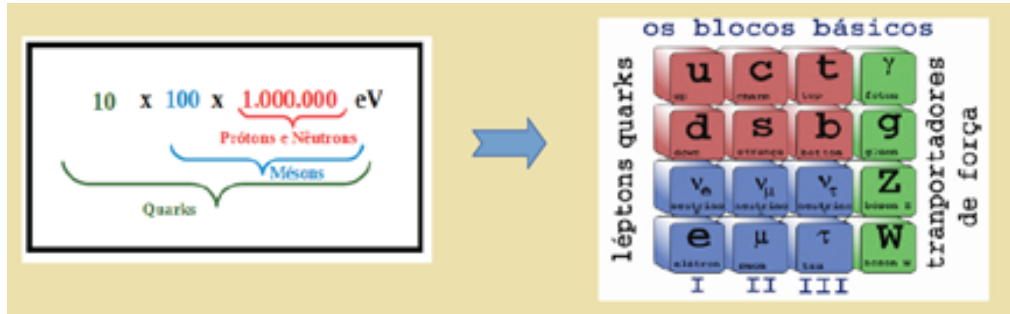

Figura 1: Quadro de Curiosidades encontrado no material didático, p.6. Fonte: Material instrucional feito por nós, Montedo P.S.G. (2017).

sem volta. Neste espaço, conforme previsto, houve um acirramento de posições e coube a nós mediarmos o debate e problematizarmos ambos os pontos de vista, respeitando-os e colocando o debate como um ponto em aberto. Enfatizamos com os alunos a necessidade de argumentos sólidos ao tratarmos de um assunto de tamanha responsabilidade, além do que, alertamos sobre o risco de em algum momento apenas replicarmos palavras de ordem, corretas ou não, sem discutirmos as nossas próprias posições sobre elas. Concluímos este primeiro dia contextualizando o que é o Plano Nacional de Energia, o que ele prevê, e a importância desta discussão em um contexto de crise energética iminente do setor produtivo.

As aulas 3 e 4 foram baseadas na apresentação e discussão de dois vídeos. O primeiro ${ }^{7}$ deles, disponibilizado pela Eletronuclear: Energia Nuclear em 2 minutos. Já o segundo ${ }^{8}$, um debate entre dois especialistas, com posições que se confrontam, discutindo: Será que o mundo precisa de energia nuclear?

\section{Do CONTEÚdo DE FÍsICA}

A partir do quinta aula, iniciamos as exposições específicas que relacionam o conteúdo de Física e a temática desenvolvida, fazendo, a priori, um apanhado cronológico das características estruturais da matéria, desde uma concepção contínua à teoria atomística, finalizando parcialmente este ponto com o modelo atômico de Bohr-Rutherford. Enfatizamos o caráter provisório destes conhecimentos, mostrando a Física não como uma ciência pronta e acabada, mas como parte do conhecimento humano construído por meio de modelos explicativos, logo, falível e com possibilidade de ser transformada/superada quando confrontada com questionamentos que não consegue responder.

Todavia, era necessário apresentarmos a existência do neutrino do elétron e dos fótons, fundamentais na compreensão sobre o decaimento radioativo. Por esta razão, fizemos uma apresentação sucinta do Modelo Padrão de Partículas, resumida pela figura 1, e iniciamos uma exposição sobre o quão bem a estrutura de um átomo pode ser observada de acordo com a ordem de grandeza da energia de uma partícula usada como ponta de prova ao colidir com o núcleo atômico.

\footnotetext{
${ }^{7}$ Energia Nuclear em 2 minutos. Disponível em <https://www.youtube.com/watch?v=OzxiQdmTD58> Acesso em junho de 2018.

${ }^{8}$ Será que o mundo precisa de energia nuclear? Disponível em <https://www.ted.com/talks/debate_does_the _world_need_nuclea_energy?language=pt-br> Acesso em junho de 2018.
} 


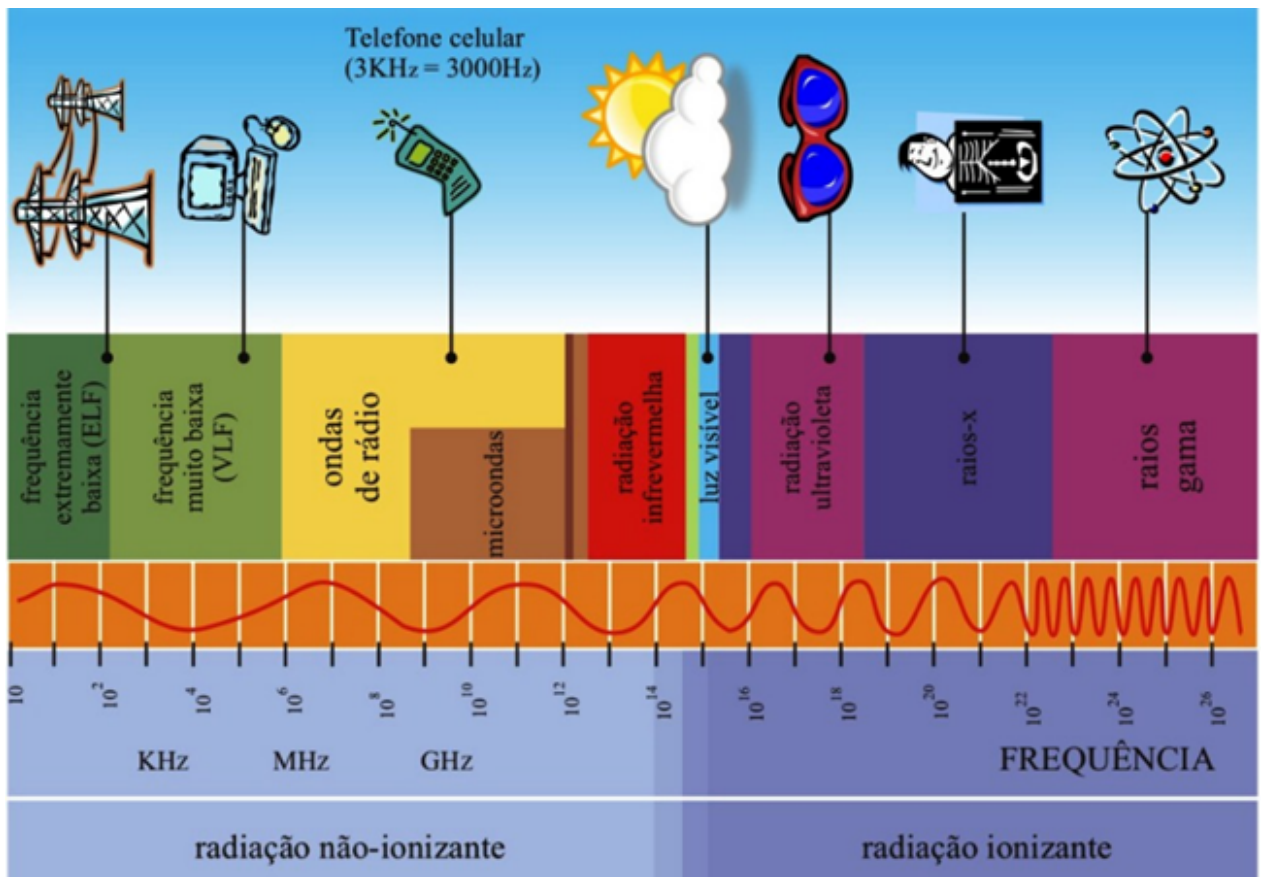

Figura 2: Espectro Eletromagnético e suas tecnologias. Fonte: http://www.astronoo.com/pt/artigos/espectroeletromagnetico.html

Nas aulas seguintes, questionamos: E se tu soubesses que diariamente estás exposto(a) à radiação, o que farias? Qual de fato é a natureza destas radiações e o quão perigosas podem ser aos seres humanos? Com o auxílio visual de uma imagem do espectro eletromagnético e suas radiações, Figura 2, a aula assumiu um contexto interessante de discussões e surpresas por parte da turma. Conseguimos caracterizar a relação direta entre os diferentes tipos de radiação e o dia a dia de cada um de nós. Além do que, nos foi possível diferenciar as radiações ionizantes e não-ionizantes a partir da quantidade de energia envolvida e a capacidade de cada uma em ionizar átomos e moléculas, podendo danificar ou não as células e estrutura genética dos seres vivos.

Com base nestas questões e elementos pertinentes às discussões que ocorreriam no Cine Nuclear, passamos a conversar sobre algumas outras ideias chaves à radioatividade, como a origem da instabilidade do núcleo atômico, fenômeno relacionado a um desbalanço entre as forças atrativas (Força Forte) e repulsivas (Forças Coulombianas) no seu interior. Apresentamos como resultado da instabilidade do núcleo uma possível emissão de partículas e/ou energia por meio dos decaimentos alfa, beta e gama. Comparamo-los em nível de ionização, poder de penetração e nocividade ao ser humano. Discutimos também a desintegração exponencial dos núcleos atômicos e o conceito de meia vida; os decaimentos nas Séries Radioativas Naturais do Urânio, Actínio e Tório; além das unidades de medidas radiológicas mais utilizadas, geralmente citadas por especialistas no decorrer dos documentários. Algumas simulações interativas disponibilizadas pelo grupo PhET, da Universidade do Colorado, foram fundamentais para que tivéssemos êxito nesta tarefa. Este passo a passo pode ser encontrado em Montedo P.S.G. (2017).

Continuamos nosso ciclo de estudos abordando a diferença entre a contaminação e a exposição radioativa, que, segundo evidenciou a pesquisa de campo, era um dos assun- 
tos a nos aprofundarmos nas discussões com a turma. Neste sentido, planejamos como complemento as discussões em sala, no contra turno, a exibição de um documentário que contou sobre o acidente radiológico com Césio-137 em Goiânia, debatendo os preconceitos, a desinformação e o despreparo técnico, dos órgãos responsáveis no Brasil, para lidarmos com aquela situação.

Dando continuidade, e entre os pontos mais importantes para a desmistificação de alguns aspectos sobre a temática, apresentamos algumas das aplicações da energia nuclear e suas radiações no contexto contemporâneo. Dentre eles: a importância da medicina nuclear na investigação de patologias e no tratamento de doenças; a irradiação de alimentos e o controle de pragas na agricultura; suas aplicações na indústria farmacêutica e aeronáutica. Buscamos mostrar que embora a radioatividade possa inferir em riscos à vida humana, quando tratada sob condições controladas, pode salvar vidas. Terminamos a aula com uma provocação: Todos vocês, ou quase todos, já comeram algum tipo de alimento irradiado com partículas gama. Quem de vocês consegue me apontar um destes produtos? ${ }^{9}$

Já no começo da 12a aula, iniciamos uma das discussões de maior interesse do curso, isto é, sobre a fissão de um núcleo atômico e suas aplicações na produção de energia. Buscando que compreendessem a origem da energia contida no núcleo, expusemos aos alunos algumas limitações da teoria newtoniana no que se refere à conservação de massa e a importância da relatividade de Einstein no contexto da Física Nuclear. Para isto, problematizamos a situação do Carbono-12, ${ }^{12} C_{6}$, que, por definição, possui 12 unidades de massa atômica (12u). Observamos que o somatório individual das massas dos prótons e nêutrons do elemento é diferente do previsto em aproximadamente 0,096u. Questionamos: Para onde foi o restante da massa? Desta forma, introduzimos o conceito físico da energia de ligação entre as partículas que compõe o núcleo atômico, isto é, a ideia de massa se transformando em energia. Assim sendo, utilizando o gráfico que apresenta a linha de estabilidade atômica por meio de uma carta de nuclídeos, figura 3 (ver página seguinte), determinamos que em um núcleo atômico, quanto menor a razão entre a sua massa atômica e a quantidade de nucleons, maior terá sido a quantidade de massa convertida em energia de ligação.

O modelo da gota líquida foi o padrão utilizado para representarmos a fissão de um núcleo atômico. Na abordagem da fissão nuclear, utilizamos como elemento pedagógico central, um simulador destas interações, disponibilizado pelo grupo PhET. Dentre os fundamentos físicos que o aplicativo nos permitiu discutir, conforme a figura 4 (ver página seguinte), temos: A fissão do núcleo atômico a partir das barreiras de energia potencial e a energia total envolvida no processo de fissão nuclear do isótopo de urânio-235; A observação das sucessivas fissões nucleares (reação em cadeia) em um processo autossustentável; A importância das barras de controle de um reator, responsáveis pela moderação de nêutrons; A diferença entre um material físsil (como o U-235) e fissionável (U-238); O enriquecimento do urânio, comparando suas interações diante das respectivas concentrações de materiais físseis e fissionáveis; A diferença entre os níveis de enriquecimento de um material utilizado para a construção de uma bomba atômica e a confecção de pastilhas de combustível nuclear.

Encerramos este ciclo com a apresentação de um vídeo ${ }^{10}$ que discutiu: Os princípios

\footnotetext{
${ }^{9}$ Batata Ruffles, produzida pela empresa Elma Chips.

${ }^{10}$ Discovery Channel Energia a Fusão Nuclear. Disponível em <https://www.youtube.com/watch?v=AmKfL_ixWPY> Acesso em junho de 2018.
} 


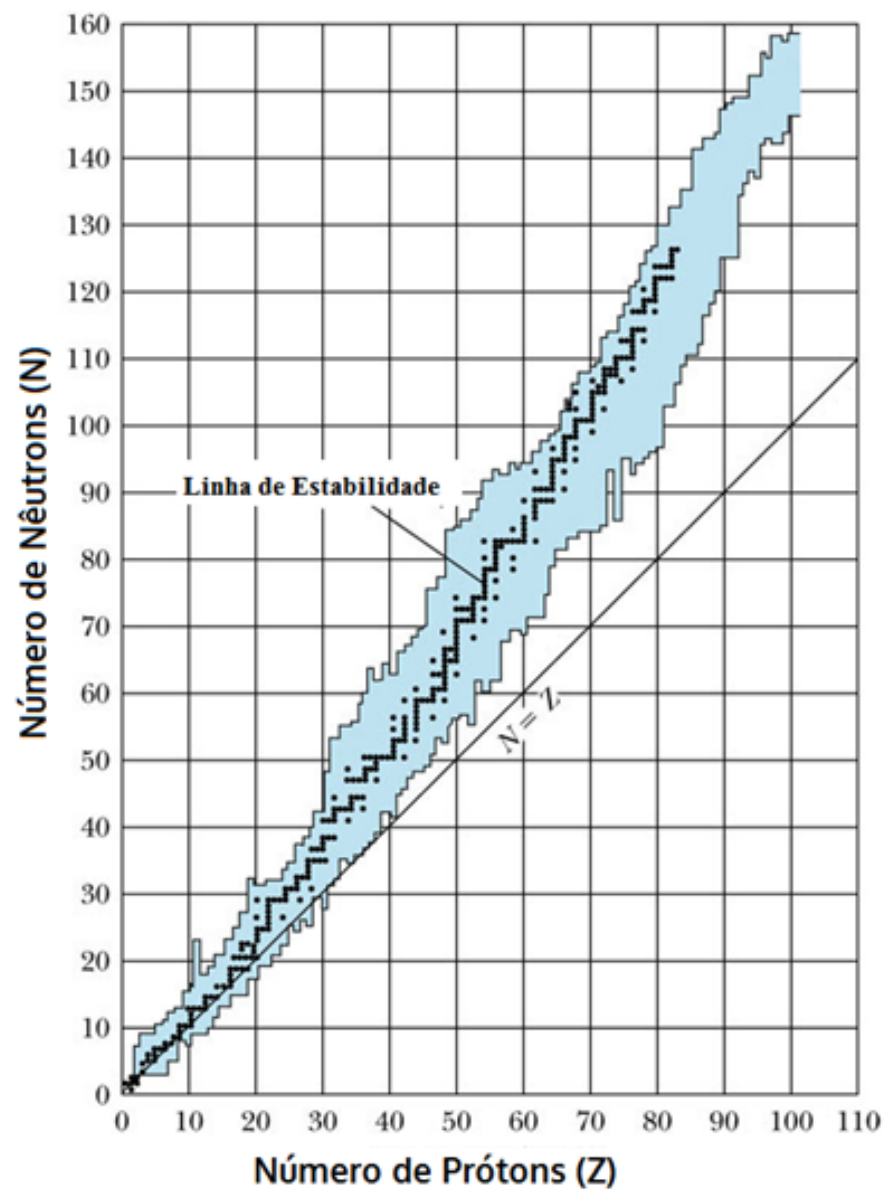

Figura 3: Carta de Nuclídeos. Fonte: 2006 Brookes/Cole - Thomnson

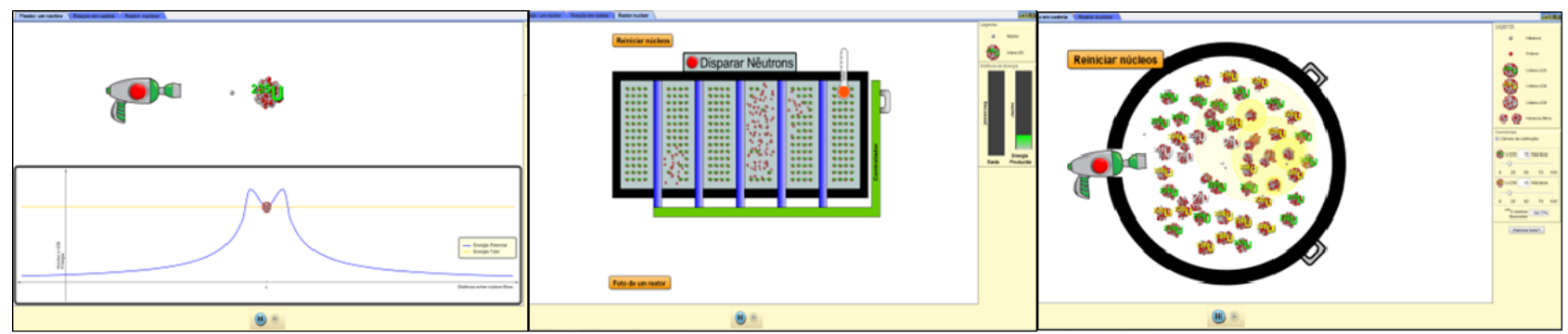

Figura 4: Imagens selecionadas no aplicativo para fissão nuclear disponibilizado pelo grupo PhET. Fonte: https://phet.colorado.edu/pt_BR/simulation/nuclear-fission 
da fusão nuclear e os seus desafio na produção de energia, comparando-o, diante dos seus prós e contras, ao processo de fissão do núcleo atômico; Apresentando os reatores de fusão do tipo TOKAMAK e discutindo suas limitações no processo de eficiência energética. Finalizamos a aula falando sobre a energia solar a partir das sucessivas fusões nucleares do hidrogênio, e suas combinações, na sua superfície, fundamentais para a existência da vida no planeta terra. Enfim, problematizamos: E se o sol não existisse mais, acabaria a vida no planeta terra? Existe a possibilidade do sol morrer?

\section{Do Brasil Nuclear}

Nas duas aulas seguintes, 15a e 16a, utilizando dados disponibilizados pelo Ministério de Minas e Energia (MME), iniciamos algumas discussões que trataram da produção de eletricidade no país, a sua diversidade no quesito das fontes primárias, e o espaço ocupado pelo setor nuclear na matriz brasileira. Este prelúdio às discussões teve origem na pesquisa de campo, a qual evidenciou o quase desconhecimento de alguns alunos sobre o setor, tanto em seus aspectos gerais, quanto específicos.

Neste sentido, devido ao evidente protagonismo das usinas hidrelétricas no setor, fizemos um comparativo entre os seus princípios de funcionamento e os de uma usina nuclear de 2a geração, estabelecendo como ponto comum a estes métodos, o gerador elétrico. Para isto, foi preciso apresentarmos ao alunos alguns pontos da lei de indução eletromagnética proposta por Faraday. Por meio de um laboratório virtual de Eletromagnetismo, figura 5, além da utilização de imãs e limalha de ferro, discutimos os conceitos de campo magnético, fluxo e a variação do fluxo magnético no interior de um solenoide, relacionando este último, ao surgimento de uma corrente elétrica induzida, responsável por acender a lâmpada. De maneira simplificada e utilizando o mesmo aplicativo, simulamos os princípios no funcionamento de um gerador elétrico e dialogamos sobre a produção e a conversão de energia, mediantes as diferentes fontes primarias utilizadas nas usinas elétricas do país. A dinâmica computacional foi fundamental para o envolvimento e participação da turma nas discussões teóricas sobre a produção de eletricidade.
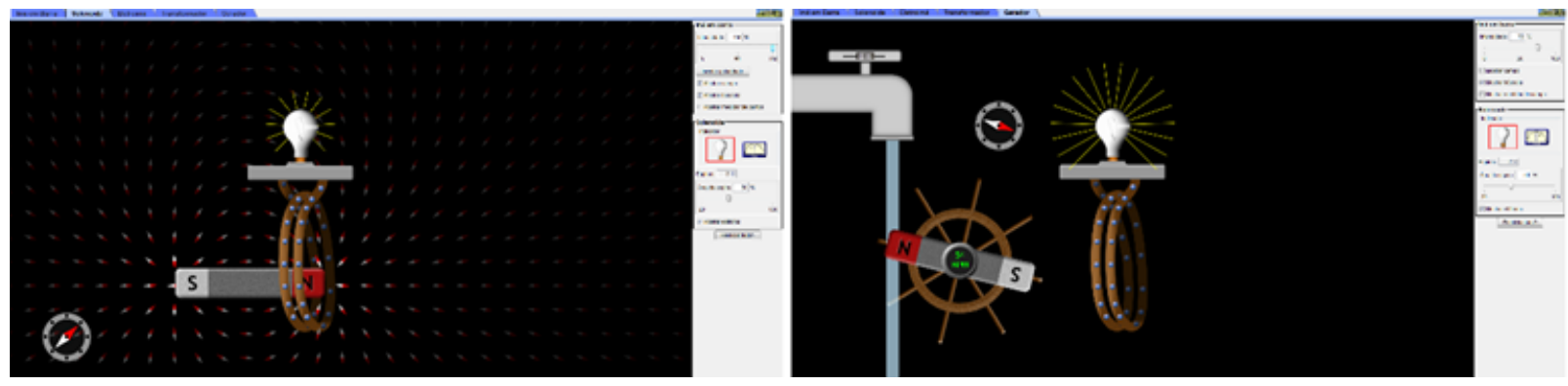

Figura 5: Imagem do aplicativo Laboratório de Eletromagnetismo de Faraday. Fonte: Phet Colorado

Continuando, tratamos de algumas informações comuns às usinas nucleares brasileiras: A tecnologia dos reatores nucleares no país; O tempo de operação comercial de Angra 1 e 2; O território ocupado e a localização da central nuclear de Angra dos Reis e a capacidade destas usinas, individualmente, abastecerem, sozinhas, grandes cidades e/ou pequenos estados brasileiros. A partir deste panorama do Brasil nuclear, apontamos o porquê o nosso 


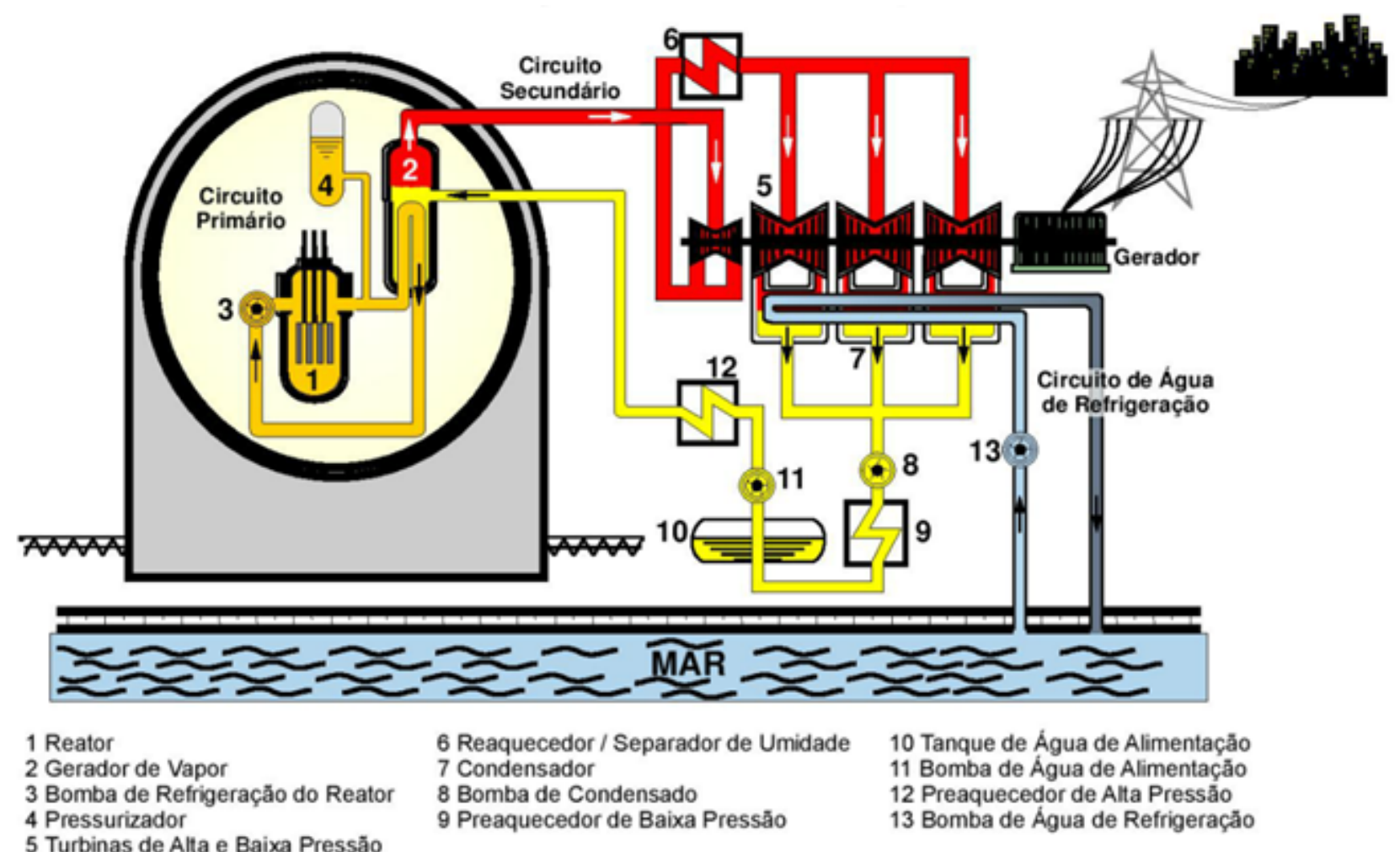

Figura 6: Imagem simplificada dos circuitos de funcionamento de um reator do tipo PWR. Fonte: Apostilas didáticas da CNEN.

país é considerado uma potência nuclear, ou seja, suas grandes reservas naturais do minério de urânio e o completo domínio tecnológico sobre o seu ciclo. Como complemento a estas informações, apresentamos à turma um vídeo divulgado pelas Indústrias Nucleares do Brasil (INB) ${ }^{11}$, sob título Ciclo do Urânio, o qual mostra desde a extração do urânio, às fases que este assume até ser transformado em pastilhas utilizadas como combustível nuclear.

As duas aulas seguintes foram direcionadas a arquitetura e os esquemas de funcionamento das usinas nucleares de Angra dos Reis. Voltamos a estudar os reatores do tipo PWR (Pressurized Water Reactor), agora de forma mais detalhada, a partir dos seus princípios de operação à base de água pressurizada, tendo também na água o seu elemento de refrigeração e no urânio enriquecido o combustível nuclear. Podemos dividir o seu funcionamento, conforme a figura 6, em três sistemas inňdependentes: (A) Circuito primário; (B) Circuito secundário e (C) Sistema de refrigeração.

De maneira simplificada, o núcleo do reator (1), parte fundamental do circuito primário, é onde ocorrem as fissões dos núcleos atômicos contidos nas pastilhas de urânio. Estas reações liberam a energia térmica que vai esquentar a água contida no sistema a temperaturas entre $600^{\circ} \mathrm{C}$ e $700^{\circ} \mathrm{C}$. Esta água, radioativa, mantém-se no estado líquido devido a um pressurizador (4). Mediante correntes convectivas, o fluido contido no circuito primário circula nos dutos que atravessam o interior do gerador de vapor (2). O gerador de vapor

\footnotetext{
${ }^{11}$ Ciclo do Urânio. Disponível em <https://www.youtube.com/watch?v=eWV1JVrR_oU> Acesso em junho de 2018 .
} 
faz parte do circuito secundário e é responsável por absorver, através do calor, a energia térmica contida no circuito anterior, aquecendo a água contida neste segunňdo sistema e transformando-a em vapor. Ambos, circuito primário e secundário, são independentes e a água radioativa contida no circuito primário não transita no interior do cirňcuito secundário. Devido a uma diferença de pressão, a água, agora na forma de vapor, percorrerá as tubulações do sistema secundário. A este movimento do fluido podemos associar uma energia mecânica, à qual irá interagir com as turbinas (5) do reator e acionar um gerador elétrico acoplado a estas, produzindo, portanto, energia elétrica. Não menos importante, o vapor de água após passar pelas turbinas vai para o interior do condensador (7), o qual está interligado com um sistema de resfriamento independente aos dois circuitos anteriores. Neste sistema, milhares de litros de água são bombeados do mar através de tubulações, as quais percorrem o interior do condensador com a missão de retirar calor. Esta água, não radioativa, voltará ao mar com temperaturas entre $3^{\circ} \mathrm{C}$ e $4^{\circ} \mathrm{C}$ maiores. Neste processo, o fluido que acionou as turbinas torna-se água líquida novamente, é bombeado e voltará ao gerador de vapor, reiniciando o ciclo até chegar mais uma vez às turbinas.

Compreendendo, de forma geral, o funcionamento do reator, passarmos a dialogar sobre seus componentes. Desta forma, compartilhamos informações sobre a fabricação da pastilha de combustível nuclear; a importância das varetas de combustível feitas de zircaloy e compreendidas como primeira barreira de contenção às partículas radioativas; as características e especificidades dos elementos combustíveis; as barras de controle, intercaladas na montagem do elemento combustível, e seu papel enquanto reguladoras da potência de operação no sistema por meio da moderação de nêutrons; o vaso de pressão, suas características, estrutura e atribuição; a função do pressurizador no sistema primário, uma das principais diferenças tecnológicas em relação aos reatores de 1a geração, do tipo BWR (Boiling Water Reactor) ${ }^{12}$, o qual por uma analogia ao funcionamento do reator PWR, também teve seus princípios de funcionamento discutidos; a carcaça de aço que protege o vaso de pressão e os geradores de vapor no reator PWR; o prédio do reator com paredes de puro concreto e até 1 metro de espessura, capaz de suportar o impacto de um boing-747 durante possíveis ataques terroristas.

Nas duas aulas de encerramento referentes à aplicação do material didático, foram apresentadas questões relacionadas à gestão dos elementos radioativos oriundos dos reatores, sua classificação de acordo com o índice de radioatividade e o tamanho do problema que já temos em mãos no processo de armazenamento desse dejetos, hoje acondicionados ainda na Central Nuclear de Angra dos Reis e sem previsão da construção de um depositório de médio prazo em território nacional.

Indispensável às discussões, por meio de um vídeo produzido pela Eletronuclear ${ }^{13}$, discutimos o plano de emergência em um possível caso de acidente em Angra dos Reis, fator que, por sua inexistência, foi determinante nas proporções atingidas pelo acidente nuclear de Chernobyl, conforme discutimos no Cine Nuclear. Alguns materiais de divulgação junto à comunidade podem ser observados na figura 7. Uma cópia deste material foi impressa

\footnotetext{
${ }^{12}$ Devido a algumas dúvidas, durante o Cine Nuclear, na exibição do documentário Segundos Fatais: A Usina Nuclear de Fukushima, o reator do tipo BWR teve uma discussão minuciosa realizada junto aos alunos.

${ }^{13}$ Plano de Emergência para CNAAA. Disponível em <http://www.eletronuclear.gov.br/Seguranca/Paginas /Plano-de-Emergencia.aspx> Acesso em Julho de 2018.
} 


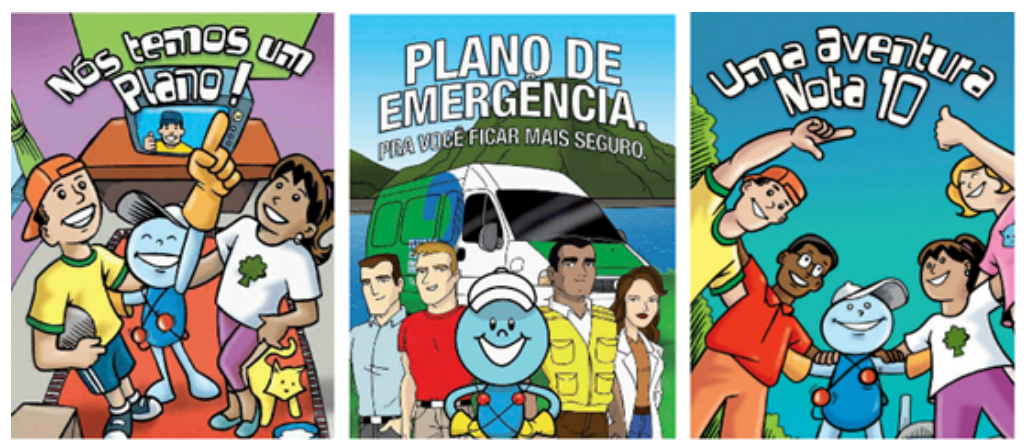

Figura 7: Cartilhas informativas distribuídas à comunidade. Fonte: Eletronuclear.

para que os alunos pudessem observá-lo e sua versão digital foi disponibilizada ao grupo.

Com o conjunto de conhecimentos desenvolvidos ao longo desse tempo e nas discussões do Cine Nuclear, finalizamos discutindo porque um reator do tipo utilizado em Angra dos Reis, PWR, poderia ter dado mais tempo ao Japão e talvez evitado o acidente nuclear nas usinas de Fukushima, as quais operavam com a tecnologia BWR. Além disso, diferenciando as tecnologias dos reatores de Chernobyl e Angra dos Reis, questões já discutidas no Cine Nuclear, avaliamos porquê uma reedição das situações de risco e erros que levaram a este acidente não se se aplicam as usinas nucleares brasileiras. Mais uma vez lembramos que nosso objetivo foi o de gerar um debate sólido, mas aberto, portanto, não tivemos receio em desconstruir discursos usados para fortalecer uma ou outra posição.

\section{Do Cine Nuclear}

As sessões do Cine Nuclear, em paralelo às aulas, foram fundamentais para que conseguíssemos mediar o conhecimento específico e alguns aspectos gerais da abordagem temática. No desenvolvimento deste espaço, além de trazermos inúmeras informações sobre episódios que dificilmente seriam trabalhados em detalhes durante as aulas, conseguimos conciliar alguns saberes científicos discutidos no período normal de aula à argumentação da turma no debates extra sala. Ao final de cada sessão, os alunos do projeto tiveram a tarega, para a semana seguinte, de escrever um pequeno relatório contendo suas impressões pessoais sobre a discussão. A figura 8 traz algumas imagens das sessões realizadas, onde foram exibidos ao longo de 8 semanas, em ordem, os seguintes documentários: - Hiroshima, o dia seguinte; - O Desastre de Chernobyl; - Segundos Fatais: A Usina Nuclear de Fukushima; Linha Direta Justiça: O Acidente Radiológico com Césio 137 em Goiânia.

\section{Da aplicação do conhecimento}

A consolidação e avaliação desta proposta de ensino se deu por meio da produção de vídeos e a apresentação dos nossos estudos à comunidade em uma Mostra Cultural, figura 9, realizada na Escola Estadual de Educação Básica Simão José Hess, em Florianópolis, SC. O grupo, com diversos trabalhos, todos em uma única sala de aula, montou o que chamamos simbolicamente de Tenda Nuclear, momento em que pode dialogar sobre o tema com colegas, pais, professores e amigos. 

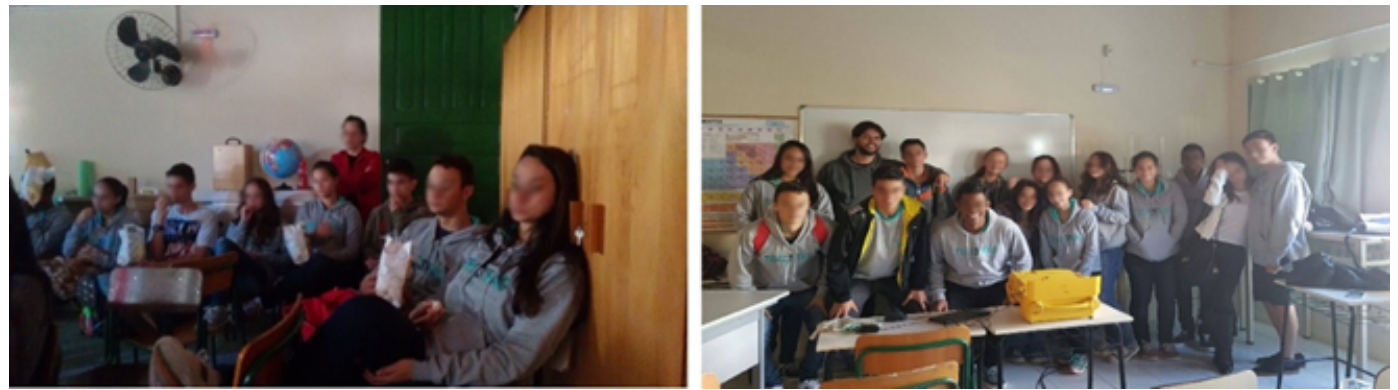

Figura 8: Grupo de estudantes durante as sessões e debates no Cine Nuclear. Fonte: Feita pelos próprios autores.

É fundamental ratificarmos que a Mostra Cultural foi construída a partir do chão de sala, onde o debate sobre energia nuclear foi colocado sob uma perspectiva aberta, cabendo aos estudantes posicionarem-se ou não. Apenas assim poderemos compreender como se deu a relação dos estudantes com o público presente, mas também, como se deu a aceitação dos trabalhos apresentados. Segundo relato da turma, a impressão foi que grande parte das pessoas esperavam uma ideia mais fechada e consonante à não utilização da energia nuclear, no entanto, desconheciam diversas questões relacionadas ao tema e ignoravam em seu discurso alguns aspectos importantes para o debate, sejam estes contra ou pró a construção de novas usinas nucleares no país. Em alguns casos, os estudantes explicaram que o objetivo do grupo não era o de firmar uma posição favorável ou contrária à questão, mas sim de dialogar sobre o tema, mostrar o que fizeram nos últimos quase três meses e apontar para importância da população, em geral, conhecer mais sobre o assunto. Um dos grupos, mais politizados, expuseram que este debate já está acontecendo e, de certa forma, sendo vencido por uma posição que não encontra resistência e respaldo popular. Evidenciou que este é um debate que tem sido negado a população em geral, mas principalmente à juventude, àqueles que serão os responsáveis por lidar no futuro com as escolhas feitas hoje. Além disso, foram visíveis as posições conflitantes entre os grupos na apresentação, até porque, refletem as subjetividades na forma como veem o tema. Embora os trabalhos apresentados na Tenda Nuclear não convergissem de maneira linear, acreditamos que a pluralidade de opiniões e posicionamentos do grupo pressupõe o que é o exercício da livre democracia, ou seja, um dos objetivos do projeto, permitir-lhes, de forma autônoma, opinar sobre a temática e posicionarem-se a partir destes debates.

\section{Considerações Finais}

A partir do direcionamento para uma política de expansão significativa do setor nuclear no país, tivemos como objetivo central deste trabalho, a democratização do debate nuclear no Ensino Médio e as contribuições do ensino de Física na qualificação das intervenções dos nossos educandos neste processo.

Segundo relato da turma, durante a aplicação do projeto as aulas assumiram um sentido melhor definido do porquê estudarem Física, ou seja, há um processo de significação na decodificação de determinados conceitos, antes aparentemente inúteis para eles. Além disso, houve um interesse maior pelos espaços construídos, com alguns alunos mostrando-se 

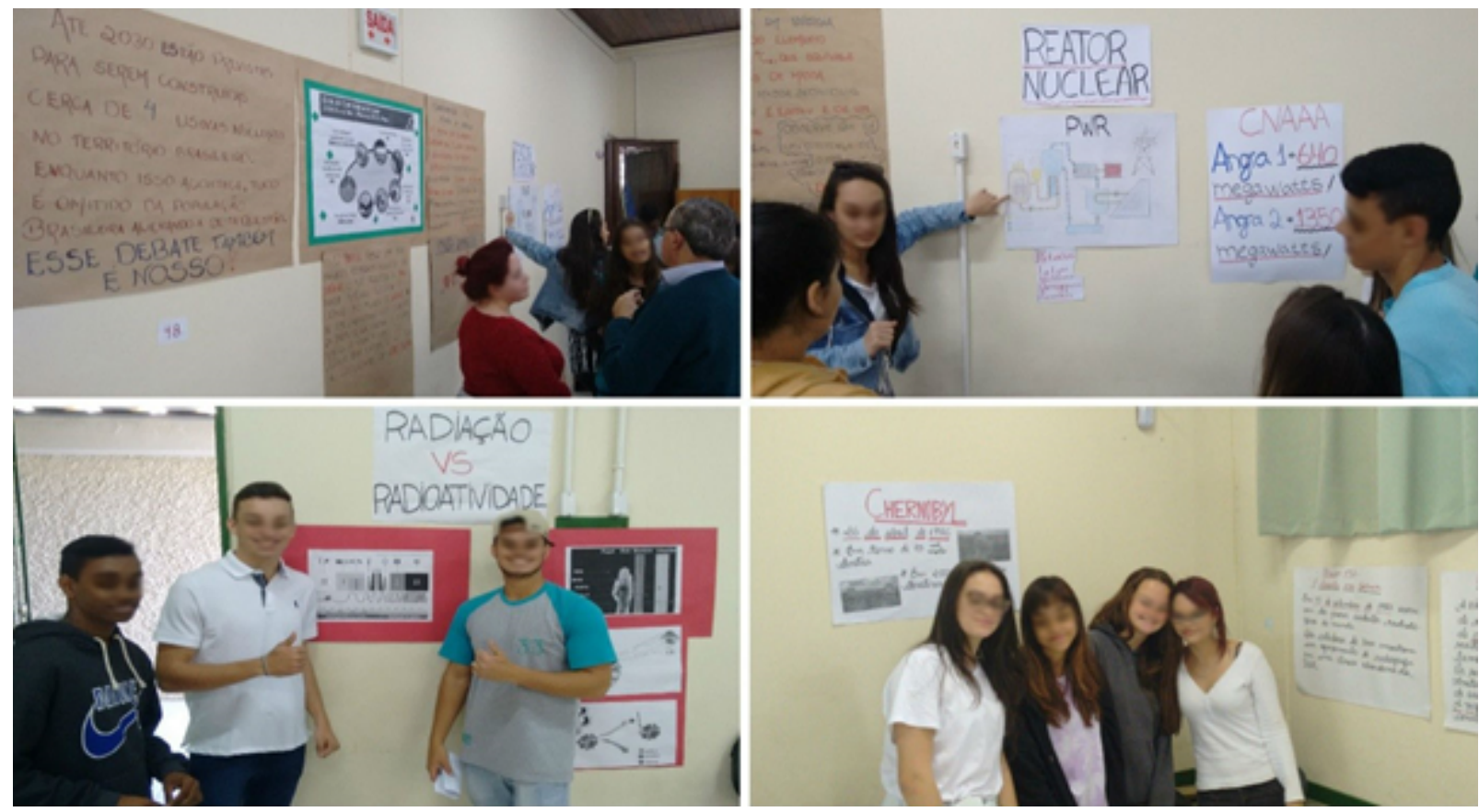

Figura 9: Trabalhos apresentados pelos alunos na Mostra Cultural. Fonte: Feitas pelo próprio autor

ansiosos para as dinâmicas seguintes. Relataram ainda que suas atividades não se reduziram ao cronograma de estudos do grupo, isto é, houveram dúvidas que geraram pesquisas com as mais diversas fontes e consequentemente provocaram novas dúvidas, por diversas vezes trazidas para o contexto de discussões da turma. Na nossa compreensão, a abordagem do ensino de Física por meio da temática nuclear assumiu um contexto diferente de tempo e espaço escolar para os nossos estudantes, trazendo um sentimento de satisfação pelo tempo empenhado não só a eles, mas a nós professores.

Por fim, reafirmamos nossa convicção de que o debate nuclear é indispensável à juventude, herdeiros das nossas escolhas e responsáveis por encontrar saídas aos problemas deixados pela nossa geração. A questão nuclear carece de novos correligionários, pessoas que abracem suas discussões de maneira crítica e aberta aos diversos pontos de vista e impulsionem um debate que não tem apenas uma verdade. Trata-se de uma questão de ordem técnica e política que entrelaça as nossas decisões à maneira como reproduzimos nossa vida no sistema capitalista. Interpretando Durkheim (1999), é preciso repensarmos nossos valores, hábitos, costumes, prioridades, de forma que consigamos superar os entraves ideológicos que condicionam nossas necessidades e respostas a formas padronizadas de conduta e pensamento, isto é, o debate nuclear nos exige a saída de uma zona de conforto, a superação de uma consciência coletiva com respostas pré-programadas. Debater energia é debater sociedade, a que temos e a que queremos. Enfim, quando o tema for energia nuclear, repetiremos, o debate também é nosso!

\section{REFERÊNCIAS}

AULER, Décio. Interações entre Ciência-Tecnologia-Sociedade no Contexto da Formação de Professores de Ciências. Tese. Florianópolis: CED/UFSC; (2002). 
AULER, D \& DELIZOICOV, D. (2001). Alfabetização Científico-Tecnológica Para Quê?,Revista Ensaio - Pesquisa em Educação em Ciências, v.3, n.1, junho

BARRAGÁN, P.; MORTIMER, E. F.; LEAL, A. Avaliação preliminar sobre o conceito de Radiação e algumas de suas tecnologias: ideias informais de estudantes do ensino médio. Encontro Nacional de Pesquisa em Educação em Ciências. Florianópolis-SC, 2009.

BRASIL. Ministério da Educação. Base Nacional Curricular Comum: Proposta Preliminar Segunda Versão Revista. Conselho Nacional de Educação; abril/2016.

CASTI, J. L. O colapso de tudo: os eventos extremos que podem destruir a civilização a qualquer momento. Tradução de Ivo Korytowski e Bruno Alexandre. Intrínseca, Rio de janeiro, 2012. 149

CUNHA. M. \& SILVA, D. Construção e Validação de um questionário de atitudes frente as relações CTS. Encontro Nacional de Pesquisa em Educação de Ciências, VII Enpec, 2009. Florianópolis.

DURKHEIM, Emile. As regras do método sociológico. [tradução: Paulo Neves; revisão da tradução Eduardo Brandão]. 1999.

EMPRESA DE PESQUISA ENERGÉTICA, EPE. Plano nacional de energia 2030 PNE 2030. Rio de Janeiro, 2007.

. Plano nacional de energia 2050 PNE 2050. Rio de Janeiro, 2015.

FREIRE, Paulo. Pedagogia do oprimido. 17. ed. Rio de Janeiro: Paz e Terra, 1987.

GUIMARÃES L. S.; MATTOS J. R. L. Energia Nuclear: Desmistificação e Desenvolvimento. In: VEIGA, José Eli da. Energia Nuclear: do anátema ao diálogo. São Paulo: SENAC, 2011. p. 26-79.

MONTEDO, P.S.G. Uma Proposta de Ensino em Física e a Democratização do Debate Nuclear: Da Radioatividade aos Princípios de Funcionamento das Usinas Nucleares Brasileiras. Florianópolis SC. 271 f. [Dissertação (Mestrado Nacional Profissional em Ensino de Física)]. Universidade Federal de Santa Catarina UFSC. 2017.

POSTMAN, Neil; WEINGARTNER, Charles. Contestação: nova fórmula de ensino. Expressão e Cultura, 1971.

RZYSKI, Barbara M.; SARTORI, Carla E. Avaliação do conhecimento da população paulistana sobre a energia nuclear e os rejeitos radioativos $\mathrm{O}$ acidente de Goiânia depertou o interesse? In: Conferência Internacional sobre o Acidente Goiânia 10 anos depois. 1997.

TANIMOTO, Kátia Suemi. Proposta de um questionário destinado a avaliar a percepção de risco relativa a um repositório de rejeitos radioativos. 2014. Tese de Doutorado. Universidade de São Paulo. 
TOLMASQUIM, Mauricio. As origens da crise energética brasileira. Ambiente \& sociedade, n. 6-7, p. 179-183, 2000 VEIGA, José Eli da. Energia Nuclear: do anátema ao diálogo. São Paulo: SENAC, 2011. 